\title{
Manuscript Title: Digital Colonialism on Digital Natives in Nigeria: A WhatsApp Usage Perspective
}

\author{
OJI, Karachi Benson, Ruth P.h.D. \\ Pan -Atlantic University, Lagos, School of Media and Communication \\ NZEAKA, Emmanuel Ezimako \\ Pan -Atlantic University, Lagos
}

\begin{abstract}
In the new media debate, digital colonialism has become a topic of serious contention. This work looks into the allegation that the internet is exploitative of digital natives' daily routine and regulates their lives by exploring this argument about the degree of consciousness of digital natives to seek out their perception of politics of Western domination in the WhatsApp usage. Therefore, the primary motivation of this paper is to find out whether digital slavery is real. Media Dependency Theory and Uses and Gratification theory form the theoretical background of the study, which utilised questionnaires to determine areas of controversy. Using a survey, we found that digital natives do not count the use of the WhatsApp as an element of colonialism. Consequently, $53.26 \%$ of the natives do not consider themselves enslaved to WhatsApp usage and thus its colonial powers; however, 28.26\% view themselves as willing slaves consequent on the benefits from using the App, while an $18.48 \%$ are unsure of their position. Based on the results, the argument is that the concept of digital slavery in terms of absolute dependence on WhatsApp is not quite appealing to digital natives, except that the amount of time they spend on it could make them enslaved, whether or not they agree. Further studies could determine the influence of internet-based apps on digital natives and the amount of time they spend, using a more extensive sample population.
\end{abstract}

Keywords: Digital colonialism, Digital natives, WhatsApp usage, Western domination, Media dependency

DOI: $10.7176 / \mathrm{NMMC} / 86-04$

Publication date: December $31^{\text {st }} 2019$

\section{Introduction}

"Data is [sic] not the new oil. It is the new land that is being rapidly colonised by corporations with the means to exploit this new resource"' (Smith, 2016 p.1). Colonialism, as conceptualised, has migrated from acquiring physical space to acquiring the human mind through the media. It has become a kind of psychological imprisonment through repetitive mass media and meddlesome digital manipulative messages that are channelled towards the entrapment of the eyeballs, ears, soul, attitude and disposition of the public. It does not require any coercive physical action or the conquering of any territory by the army of fortune claiming to be on a civilising mission but works its way through subtle persuasive packaging to enslave large audiences and nations. The internet's extraordinary nature is coupled with that of the imperialist period. In the past, colonial land ownership was a matter of capital accrual, but now stakeholders are digital topographers, generating cybernetic space to discover new commercial territories. They are creating new territory and workforce through technological firms, a variety of digital colonial hierarchy. Jandrić and Kuzmanić (2015) corroborate this statement by insisting that the ancient standard of producing the savage is a purely moving course: instead of making the savage from individuals found in the new terrains, digital colonialism has moulded the savage from persons who are left behind in the old milieu. This digital psychological empire uses the means of hegemonic language (in this case, English) projected by the dominant media to acquire and enslave people all over the world (Omoera, 2010). The digital colonialism is championed by the Global North, as it was in the colonial era. Through behemoth media multinationals like Google, Facebook, WhatsApp, Twitter and a host of others, have corralled the Global South with a plethora of media products that are very difficult to resist or ignore due to lack of capacity to wedge this influence but to consume whatever that is produced by the West. This is the thrust of the new digital colonialism. The way this happens and the impact on individuals will be the principal concern of this paper because there is a tacit link between colonial legacies connected with western industrial development, market consumerist tradition and digital imperialism as they possess the same pattern of universal consumer culture (Iqani, 2017). Ali (2017) in the same vain observes that "the invocation of colonialism in informative discourses include explicit recognition within the discipline of 'postcolonial computing' of a 'colonial impulse' within ubicomp, analogically formulated concerning 18 - $19^{\text {th }}$-century British colonialism' (p.3).

Digital colonialism includes not only the ability of the media to regulate the activities of the individual but also of institutions and even nations through the internet, technology and the mass collection of data to predict influence and even disrupts behaviours (Mills et al., 2016; Torbel, 2019). This means that social networking sites also have in possession of our daily comportment that would enable them to manipulate our lives and that of 
nations. For instance, Cambridge Analytica, a network company working with Facebook has been able to disrupt the political life of countries like Kenya, Nigeria, Bolivia, Latvia, and probably the United States, by influencing the outcomes and mining of the data of opposition politicians (Blumenthal, 2018; Solon, 2017). These western media conglomerates have taken advantage of the digital vacuum to invest heavily on the internet and artificial intelligence to regulate all aspects of our life, thereby challenging individuality and threatening the security of nations (Eijaz \& Ahmad, 2011). They have gone beyond national boundaries and cultures to mine data, which they use for the control of individuals and profit. By this position, Jin (2015) points out that "platform owners who are mega media and technology giants have developed their strategies to appropriate user activities in order to transform users' daily performances in monetary revenue resources"' (p.185). Anderson cited in Smith (2016) also gives an insight into the gain they have made by mining the data:

We need to look no further than Microsoft's USD 26 billion acquisition of LinkedIn or Facebook acquisition of WhatsApp for USD 19 billion and Instagram for a mere USD 1 billion and AT\&T's USD 14.2 billion valuations of the value of its data assets as stated in annual reports. When you investigate the values involved in data assets, the figures are staggering. It would be fair to say that most people have no idea how much their data is truly worth. (p.2)

Thus, these global brands would "colonise weak local practices and at worse erase and at best, appropriate and profit from them" (Iqani, 2016). For example, about 90\% of the internet and media consumables in Nigeria are imported from the West. The IT companies are mainly engaged in maintenance and add-on on finished products. Some are not aware that this vacuum has created a "digital productivity gap" that is exploited by the conglomerates because they are in perpetual control of search algorithms, thereby monitoring and determining digital platforms and universal culture.

This control of the media and digital space by the Global North has led to the psychological imprisonment of the digital natives in the Global South who have albeit unwittingly migrated into the digital colonialism with relish. Today, a generation of young people born into the internet era is immersed in the digital world. Researchers believe that their brains are wired differently by internet technology because of early involvement with technology (Lin, 2008; Herther, 2009; Crist, 2017). In consonance with this observation, Dingli \& Saychell (2015) see them as individuals bound by technology from their birth. Being bound means that they are in certainty, exposed from birth to technology. These natives are influenced heavily by internet conglomerates and prefer receiving information and processing it at the speed of light as they adhere to multitasking and active learning (Prensky, 2001). They are born into the colonial culture of Apple, Facebook, WhatsApp, Uber, Taxify, Twitter and a host of other pervasive Apps perpetrated by the conglomerates of the Global North that have infiltrated their lives to the point of omniscience that they have adopted it as part of their culture (Patson, 2014).

Based on those as mentioned earlier, this paper intends to look at how the digital natives in Nigeria conceptualise digital colonialism. Do they see it as a reality or a fallacy? Have they willingly accepted to be addicted to the internet conglomerates because of the perceived benefits? Particularly, to help people relate to the current criticism, this paper will investigate the level of digital colonialism among digital natives in Nigeria through the media messaging application - WhatsApp (assumed to be the most popular App among the youth in Nigeria) - (Cchub, 2014; Muyiwa 2015; Smith, 2017; Similarweb, 2018).

\section{Conceptualisation of terms}

\subsection{Digital Slavery:}

Slavery has been since the existence of Homo sapiens. It is a condition of servitude in which a human being, after purchase, is subjected to the whims and caprices of another person. They are perpetually attached to the purchaser who is at will to use them as he deems fit. As Ogunsola (2005) points out, "Another characteristic of slavery is the fact that the slave was deprived of personal liberty and the right to move about geographically as he desired". The main thrust here is that a slave is eternally attached to the master who has bought him or her. At this juncture, one may wonder how this is related to the notion of digital slavery. The old slavery involved geographical conquest and then subjugation by a stronger party, while digital slavery is about the conquest of the territory of cognition and the mind by devices developed by the conglomerates as we know them: Facebook, Google, Twitter, WhatsApp, Netflix, Uber, and a host other internet App. According to Rogerson (2018), just like in physical slavery, new groups of people arrive and permanently settle while retaining the commitment to the homeland. The virtual world is undergoing colonialism. The conglomerates show a permanent identity and are sustaining permanent manifestations. Their modus operandi remains aligned to the organisation and the location they come from (The United States and Europe - the Global North). The present aboriginal virtual inhabitants are forced to align to the dictates of the colonisers, and they stand the danger of being forced to conform to the dictates of slavery and servitude of the settlers, being pressurised into conforming to the norms of the new virtual settlers.

Therefore, digital slavery from our conception is that sense of physical and emotional attachment to 
technology, in this case, internet applications, to the extent that it regulates one's life. This may originate from an apparent connection to internet devices to the extent that there is a dependency syndrome, that an individual feels distraught without it. It is a constant desire to be online to the stratum. Digital slaves are not able to master the technological world effectively; instead, they are enslaved by it (Moody, 2014; Illing, 2018). Anderson (2010) captures this situation graphically:

You wake up and check your email on your bedside iPad-that's one app.

During breakfast, you browse Facebook, Twitter, and The New York Timesthree more apps. On the way to the office, you listen to a podcast on your smartphone - another app. At work, you have Skype and IM conversations. More apps. At the end of the day, you come home, make dinner while listening to Pandora, play some games on Xbox Live, and watch a movie on Netflix's streaming service. You've spent the day on the Internet (par. 3)

A manifest attachment to the media is just the bid by an individual to make self-presentation. The new media, as much as it takes in its prevailing advantages, also holds tremendous challenges to its users. In the world today, evidence documenting digital slavery can be seen from all parts of the globe with the advent of globalisation, which is exploited by the conglomerates through the illegal harvest of personal data (Ogunsola, 2005). This is underscored by Jandric \& Kuzmanic (2015) and Mule (2000) who point out that the imitation of the new digital spaces is embarked on by the ruling classes as a device for (re) construction of the prevailing hegemonic social relationship, and they maximally exploit the situation effectively. Consequently, this condition can be equated to physical slavery because based on Lefevbre's (1974) argument, the media world is a fully developed representation of physical, pecuniary, social and etymological terrain. People are subjugated more than ever through the internet because our life now almost depends on the internet. Jin (2015), points to this mindless symbiosis, observing that in the epoch of globalisation, platforms have also gained importance for the digital economy as people, both as content developers and users, consistently use Facebook and Google for profit, thus becoming a new means of capital for the owners who have developed their strategies to transform daily users' actions into financial sources. The way people attach to the new media that is dominated by the conglomerates indicates that modern slavery and imperialism is back, this time through the new media application. They are not just latent. A related instance was the Cambridge Analytica scandal in 2018 when 87 million data profiles were harvested on Facebook through digital personality questions (Rogerson, 2018) and used for commercial purposes without authorisation. Our position here is that digital manipulation by the conglomerates is the extension of the hitherto territorial slavery in algorithmic guise.

\subsection{Digital Natives:}

Digital natives, a term probably first used by Mark Prensky in 2001, describes the generation born into the internet world. They grew up where the application of the internet abounded and intermingled with their everyday intellectual, emotional and social development. This category of people are those born in the 1980s and 1990s, who have access to all networks and the capacity to use them effectively in their daily routine (Presky, 2001; Zur, 2011; Alexander, 2015; Rochi, 2009). As inhabitants and natural speakers of the internet language, they use the technology seamlessly, finding it challenging to inhabit the two worlds of human existence - the analogue and the digital (Ronchi, 2009). They dwell on the latter, as they have the connection to all networks and the capacity to use them to solve problems without the approval of their parents. Also, they are voracious listeners of music and watch a large dosage of movies through the media and are very creative with the devices (Palfrey and Gasser, 2008). Furthermore, they are gifted in accessing pieces of information faster through digital formats instead of printed books, as they have nascent means of assimilating new information (Stole, 2018).

Mark Prensky (2001) harps on these characteristics, pointing out that they trace information faster and multi-task through visuals and texts, performing best when connected to the internet and appreciate instant gratification. Additionally, they prefer to play games on the net instead of doing challenging work (Prensky, 2001a, 2001b; Martins \& Mandy, 2010). The internet has redefined the lives of this net generation that it predetermines the modus that young people react to situations, produce, and accept new ideas. Consequently, this has a profound implication on their lives because as researchers want to prove, their brains may have been reconfigured by the media-saturated world. Accordingly, Dingly and Seychell (2015) indicate that they are openly directed by the new media which has regulated their routine. Alternately, researchers have questioned this concept of neuroplasticity as postulated by the school of Mark Prensky. They interrogated the concept based on the date, period of birth, exposure, and cognition of the digital natives. More recent exploration is required in this regard.

\section{Statement of the Problem}

The internet and the new media have definite advantages in the modern world as people now use them for multiple purposes. It is estimated that in 2018, 4.1 billion people connected to the internet globally 
(Statistica.com, 2018), and 103 million people connected in Nigeria as of 2018 (Premium Times, 2018). The internet is so pervasive that it has permeated all the ramifications of our life.

However, critics insist that the internet is exploitative, and has the vestiges of colonialism in the new guise. Consequent on the ways it has appropriated and exploited our daily routine through the accumulation of personal data and the regulation of lives, that people now postulate it to new imperialism by the Global North as it was during the epoch of physical colonialism.

Therefore, in response to these allegations, this paper investigates the extent that the internet has perpetrated colonialism through the deployment of WhatsApp on the digital natives in Nigeria. It also examines if this has aided a new phase of imperialism.

\section{Research Objectives}

The internet is very omnipresent, especially with the digital natives who have adopted it as a modus operandi. Scholars are still researching on the impact of the dependence on the internet on the psychology of digital natives. Consequently, the thrust of this paper emanates from the quest to broaden the knowledge in this area of research. Specifically, this paper seeks to:

1. Determine the level of exposure to WhatsApp and other western-based Apps by digital natives in Lagos, Nigeria

2. Find out the level of influence of WhatsApp on digital natives in Lagos, Nigeria

3. Ascertain whether the digital natives see themselves as slaves of the internet through WhatsApp usage

\section{Research Questions}

1. What is the level of exposure to WhatsApp and other western-based Apps by digital natives in Lagos, Nigeria?

2. What level of influence does WhatsApp usage have on the disposition of the digital natives?

3. Do digital natives see themselves as slaves to the internet?

\section{Theoretical Framework}

\section{Media Dependency Theory and Uses and Gratification Theory}

Early media critics in the 1960s and 1970s have made several attempts to theorise human craving for the media. This work is set within the purview of Media Dependency Theory (MDT) developed by Sandra Bell-Rokeach and Melvin Defleur in 1976 and Uses and Gratification Theory by Elihu Katz and Jay Blumber in 1974, to determine digital colonialism among Nigerian digital natives.

The first theory provides a viewpoint that people generally depend on the media for gratification, positing that audiences and the media should be examined based on more significant social dynamics and complex dimensions between them. This is because they thirst for information about situations and rely on the media for the satisfaction they believe that the media will provide (Syallow, 2015). These media effects are the type that will enlarge people's belief systems and attitudes, thereby motivating delicate transmogrification in personal or group sentiments as well as other types of attitudinal modifications.

\section{Figure 1: See appendix}

In essence, the theory points out that the individual becomes more dependent on the media when it has his or her needs gratified, especially during social upheavals. Therefore, the degree of dependence on the media would be hinged on the availability of information at the disposal of the audience. This challenges one of the core assumptions of MDT that people are only dependent on the media once they are satisfied. Nevertheless, there are lacunae in the theory that may necessitate further inquiry. It should be pointed out that people now do not rely on a single medium as they may decide to switch loyalties at any time due to circumstances and the relevance of the media. For example, professionals may see LinkedIn as more relevant to their business than Twitter. Again, value propositions may also separate people from the type of media they use; this may rely on culture, convenience or just personal preference which may make the individual to shift loyalty to other media, as Zengotita (2005) points out:

The real world is reconstituting itself on a plane that transcends ancient solidarities of nature and custom, craft and industry. The whole process has been accelerated since the invention of modern communication technologies (the telegraph, the photograph, the telephone), and it crossed a qualitative threshold in the past couple of decades, with the rise of new media' (p.24)

Putting into consideration the recent development of the new media, which has individualised human perception, the Media Dependency Theory needs to be re-evaluated to include individual divergences on the dependence on the media. According to Syallow (2015), it is quite hard to prove the practicality of media dependency as the information is individual dependent; it is quite challenging to measure the rate of addiction, which points to the fact that the individual determines the rate of addiction. This view agrees with Anaeto, 
Onabajo and Osifeso (2012) that '. ... the receiver determines what is going to be absorbed and does not allow the media to influence them otherwise", (p.70).

Given this, the Media Dependency Theory needs to be further expanded to include the latest trend in the new media to accommodate discoveries, experiences, and development. Apart from these lacunae, other factors, and individual preferences may influence the permanent attachment to the use of the media. These factors could be elaborated within the framework of Uses and Gratification Theory by Elihu Katz and Jay Blumber in 1974, which attempts to comprehend why people select specific medium against the other. According to Csikasz (2017), UGC has a positive approach in the sense that the theory is founded on the connexion between the user and the medium are, in fact, capable of identifying their own needs and choosing a medium accordingly.

Here the focus moves from the media influence to the selection of the media type. Therefore the onus lies with the people to regulate usage and application. This theory attempts to answer the question of what people do with the media instead of the effect of the media, as postulated in the Media Dependency Theory. This reaction theory pays attention to the consumers and the producers of the media, as the audience here is considered to be overly active in the selection of type and not passively receptive as suggested. This is a reminder of what McQuail (2010) referred to as 'taste culture' and 'gratification set' where the audience selects the type of media based on designated interest because of the aggregation and dispersal of individuals without standard connection, except for convergence of interest.

However, the theory is also fallible in certain areas as absolving the media of duties and responsibilities to the public. Secondly, it also plays down on the application of ethics of media production, as this has been shifted to the audience. Also, it wholly relegated the obligation of the duties of the media to society and shifted that to the audience. In all, these two theories complement each other; what the former lacks the latter supplements. Therefore, they would need further research to be abreast with the latest development in the new media. The synthesis of the two theories could usher in a new theory that would take care of the challenges. The postulations of these two theories agree with the framework of this research.

\section{Literature Review}

The plethora of academic texts on this topic is overwhelming; they are all concerned about how the conglomerates are systematically colonising the world, especially the digital natives and the Global South. Google, Facebook, Twitter, WhatsApp, and Snapchat dominate the internet through social media to regulate our lives. (Iqani, 2016; Dengli \& Seychell, 2015; Ebner \& Schiefner, 2010; Galtung, 1990). To further drive home, this issue of the diverse and intrusive nature of the internet through Google, Noble (2018) corroborates and describes the situation luridly:

Google has become a ubiquitous entity that is synonymous for many everyday users with "the Internet" itself. From serving as a browser of the Internet to handling personal email or establishing Wi-Fi networks and broadband projects in municipalities across the United States, Google, unlike traditional telecommunications companies, has unprecedented access to the collection and provision of data across a variety of platforms in a highly unregulated marketplace and policy environment. We must continue to study the implications of engagement with commercial entities such as Google and what makes them so desirable to consumers, as their use is not without consequences of increased surveillance and privacy invasions and participation in hidden labor practices. (n.p)

The near-total algorithmic dominance of humans enhances the total control of human life by regulated human engines.

The thrust of this section is to strategically, through a holistic approach, analyse the existing related scholarly literature on the evolution of digital colonialism and the impression on the digital natives. As extant literature has established, the conglomerates are engaged in one way media flow from the north to the southern hemisphere, and social content dominates the tide of information to all aspects of living that people's character is somewhat determined by these (Varis, 1984).

The same view is held by Thussu (2000) who argues that this flow has been persistent through images and ideas at the epoch that the media has been increasingly universal and with the surge of media, transnational traffic has been to the advantage of the multinationals. Though there has been a recent flow of information from the south to the north with the emergence of Brazilian TV, Al-Jazeera and Al Arabiya, this has caused an alternative media flow. The West still regulates the area, the hierarchical media configuration - and the hegemonic monopoly will last for a long time (Guo \& Vargo, 2017).

The consequence of this is what Galtung (1990) called cultural violence on the consuming nations, which will result in the violation of cultural ethos that the victimised sees it as a usual way of life. This is consequent on how the borderless system of the internet has rendered the regulation of the internet impotent, there seems to be 
no limit in regulating communication, and the terms of the ITU (International Telecommunication Union) on communication have been subjugated by the media giants (Mathiason, 2009). This gives an ample chance for the controllers of the media to foist their ideas on the consumers who are mostly helpless due to the overwhelming system that forces them to consume media products that may be at variance with their philosophy of life. It is through this chaotic one-way traffic that digital natives are domesticated into the cyclical system.

This digital epoch has transformed the way people interact with one another and their immediate environment. The older analogue audience is also incorporated with the nascent culture as digital immigrants. Though they rely heavily on the analogue system, they are also sophisticated in their use of the internet. The variance is that the digital natives inhabit in their devices online without boundaries between online and off-line. Their real space, digital space and time are synchronous. This is seen as the onset of colonialism because through this; there is a dependent union existing between the South. The media torrent from Europe and America drown the indigenous cultures of the universe but is worse in the Global South because of the skewed superiority of the conglomerates that regulate the media sphere in the technology and the development of media content.

Therefore, it is quite clear that the United States and Europe are focused on conquering the world through information ascendancy (Miller, 2004). This becomes persistent because the consuming nations lack the technology and the finance to wedge the tide, though it must be given that at times there is a flow from the south to the north with the recent development in cable television technology in what seems to be a "glocalisation", where the local becomes global. A good example is the Al-Jazeera network from the Middle East that beams to the world and some local stations that beam into Europe and the USA. This stands for the power relations which control the mind through the technological surface; hence, it becomes the social reality which should be navigated carefully as the text is also a social product. As globalisation, finance, and imperialism are synchronous (Appandurai, 1996), they rely on the economic system constructed of industrial and financial projections. Hence superior technology can dominate the economic sphere. These colonial legacies have also shaped the media consumption, deploying in the media presence outside the western world, where they project imperialist stereotypes in the portrayal of the Global South.

Africa is at the receiving end of the digital expansionism. The digital native is absorbing all the traits of digital imperialism without the least awareness (Kwet, 2018). The presentation of Africa in the western media has always followed the route of subjugation, colonialism, stereotypes, racism and particular meaning to produce a romantic representation in terms of relations to the power to and control between Europe and the southern hemisphere. This has evolved into a systematic way of communicating and writing, which involves specific "lexical sets and syntactic structures" (Brookes, 2014) that gave rise to specific interpretations. The inability of Africa to perform in this sector of the world economy has made her a digital colony of the West, thereby her compromising sovereignty without being conscious of it. As a result, it has become a dumping place for outmoded technological programmes and goods (Omeruo, 2012). Due to this challenge, the youth is falling victim to digital colonialism because all they possess are not made in Africa. The conglomerates have come to dominate all aspects of existence. For example, in South Africa, Google takes about $70 \%$ of local online advertising; Facebook controls 12\%, while Netflix has a considerable fellowship (Kwet, 2018). They cannot be challenged because of the lack of capital and technology, thereby creating cultural, social and economic hegemony. Again, the language of the internet is English; people have to scramble to learn it to manipulate the internet. Statistics show that $60 \%$ of the web content is in English, and only 10-15\% of the world speaks it (Mills et al., 2016). This means that a considerable population also is denied access and is indirectly forced to learn the significant language of the internet, which is the English Language. In another typical example of digital slavery, Facebook through a program in Kenya called Free Basic, which is purported to be free internet for the growing market, pays attention to different content at the neglect of the local ones. This is against the net neutrality principle (Solon, 2017). The project neither serves the local needs, nor does it bring people online; all it does is data harvesting for commercial purposes. A study carried out on Free Basic in Kenya indicated that the program is tilted towards western orientation. Ellergy Biddle, cited in Solon (2017), insists that Free Basics "turns the user into a mostly passive consumer of mostly western corporate content; that is digital colonialism" (p.2). The conglomerates are only pushing for their business interest through digital means.

In Nigeria, the situation seems more pathetic because of the same prevailing circumstances; the digital natives are so immersed in the new media that they are not aware of the situation in question. The imperialistic strictures have compelled most users to toe the line of the conglomerates as the continuation of the hitherto mercantile colonialism (Hamilton, 2016). It has become a continuation of physical colonialism through the internet, accepted willingly by the colonised. Nigeria has been in contact with the western media for a long time more than most African countries (Omoera, 2010) in all aspects of life. However, it must be pointed out that western nations do not see this as an aberration because of its consistency. Also, the digitally colonised see this as usual, even though they are conscious of the damage and exploitation; but they are powerless to stem the digital invasion due to poverty and corruption that pervades the socio-political system. Nigeria has not been able to enact its media resistance; citizens are forced to depend on western media products, instead of having those 
produced by locals for internal consumption.

From those above, the reality of digital colonialism is evident and pervades the whole digital structure; in fact, the conglomerates depend on that for economic gains. To further clarify this situation, WhatsApp, one of the dominating media applications, is used in this study to determine the level of the pervasiveness of digital slavery on the digital natives.

\section{Methodology}

The population for this study is undergraduates of the Pan-Atlantic University, Lagos because the school affords its students access to free Wifi all day long. Given this enabling facility, students have access to data that enable them to browse and use applications for chats and other purposes. Because this study focuses on digital colonialism and the presence of digital natives online, Pan-Atlantic University students provide a good fit for the study.

Pan-Atlantic University is a relatively small private school located on the outskirts of Lagos Island. The total population of Pan-Atlantic University undergraduate students is 700, working with this population, a sample size of 249 was estimated at $95 \%$ confidence level and 5\% margin of error. Two hundred forty-nine students were recruited to participate in the study using the simple random sampling technique. Researchers sent out links to random students to give every student in the university an equal chance of being selected. At the end of the data collection, only 129 students had responded, giving a return rate of $52 \%$ (The reason for this may be that some students would rather chat or do other things online than fill online surveys). The responses were further screened using screener measures like age (participants were expected to be between 15 and 31 years old to qualify as digital natives) and presence on WhatsApp. In the end, the researchers were left with 92 valid responses.

The research tool used to gather data was the questionnaire. The questions were based on the objectives the study sought to achieve. The researchers sent out the questionnaire via emails to students, using Google Docs. The data received were then analysed quantitatively.

Regarding the method of data analysis, quantitative data were analysed using tables and graphs, in line with the research questions postured in this paper. Different aspects of the questionnaire helped to answer the research questions, and the responses are also discussed.

\section{Analysis}

This section deliberates on the data gathered from the respondents of the questionnaire. The charts below present the gender and age distribution of respondents, followed by a discussion of the demographics of the study participants.

Figure 1: see appendix

At the end of administering the questionnaire via the online platform, the results collated showed that there were 55 male respondents and 37 female respondents representing 59.78\% and 40.22\% respectively. Our respondents are from five out of the six geographical regions in Nigeria with South East ranking highest $(42.63 \%)$, followed by the South West (27.9\%). 99.2\% of the respondents have access to data/internet on their device, and they all have and use WhatsApp. $31 \%$ of the respondents visit the internet every 5 minutes, whereas $14.7 \%$ visit very often.

Subsequently, the three research questions are addressed one after the other, using data from the respondents.

\section{Research Question One:}

What is the level of exposure to WhatsApp and other western-based Apps by digital natives in Lagos, Nigeria?

As shown in Table 1 below, the researchers focus their findings on the results from the 92 digital natives. There were 55 male respondents and 37 female respondents, representing 59.78\% and 40.22\% respectively. This is an adequate representation of male and female respondents in the digital native group. All 92 respondents use WhatsApp, with 80 of them as active users representing $86.96 \%$. In comments to follow as responses to other questions, it is observed that many of the digital natives also use apps like Instagram and Snapchat, amongst others. This confirms that the digital natives are aware of the almost inevitable use of social media, especially WhatsApp, to communicate and that they have a high level of exposure to these western-based apps.

\section{Table 1.See appendix}

From the table above, we see that 80 out of the 92 respondents affirmed being active users of WhatsApp, which implies their exposure to and usage of similar apps for communication purposes. Even the remaining 12 that do not consider themselves active users of the WhatsApp do so occasionally.

\section{Research Question Two:}

What level of influence does WhatsApp usage have on Digital Natives?

In addition to the above table, the optional responses allowed for in the questionnaire had 20 digital natives affirming to the level of influence WhatsApp usage has on them. They all agreed to the use of WhatsApp, and 
the fact that it is beneficial to them in ways that include;

"communicating with family and friends", "communicating with people I can't see', "communicating with loved ones using the video feature, especially when I am very far away from them", "engaging, well with my friends", "having more closed up interactions", "chatting with persons I don't even know", and "using it for informational purposes".

Also, on the amount of time spent chatting using the App, in a range of 1 5, $6 \sim 10,11 \sim 15$ and $16 \&$ above, a higher percentage $46.74 \%$ responded that they spend a maximum of 5 hours each day chatting on WhatsApp. We also had $19.57 \%$ of respondents who use 16 and above hours daily on WhatsApp. Regarding the second research question, it may be deduced thus that there is a large amount of influence of WhatsApp usage of the digital usage, since it takes quite a significant amount of their time, for whatever purposes they deem fit for it. Their time spent on the App is captured in Table 2 and Figure 2 below.

Table 2: See appendix

Figure 2.See appendix

Research Question 3:

Do digital natives see themselves as slaves to the internet via WhatsApp usage?

To properly interrogate this, the natives were asked questions to ascertain their addiction or otherwise to the use of WhatsApp. Further questions were also asked to find out if they considered themselves digital slaves as a result of the benefits they derive from the use of the App. Table 3 reveals that $53.26 \%$ of the respondents do not feel that they are addicted to the use of WhatsApp whereas $28.26 \%$ responded that they are, indicating a not too engaging platform for the more significant respondents.

\section{Table 3. See appendix}

Figure 3: See appendix

In addition to responses to structured questions received via the questionnaire, optional comments by 20 respondents in line with ascertaining their addiction to WhatsApp usage or not had varied responses. Some preferred not to answer the question in clear terms but merely the following:

"It can be quite distracting", "It can be quite addictive", while others clearly stated, "I used to be addicted to it until my mum helped me", I am not addicted to it", "Not at all. There are other social media platforms that I relate better with than WhatsApp", "No, I can always put my phone down", "I am not always on WhatsApp", 'Too much of everything is bad, so I don't get glued to WhatsApp," "In fact, I check WhatsApp only twice a day", "There are many important things to be done than being on WhatsApp", "I'm not addicted to its use", "I'm not always on WhatsApp", and "I barely use it. Snapchat and IG do it for me".

These responses thus show that even though there is widespread use of the App by digital natives and that much time is spent by a good percentage, most of the digital natives studied do not consider themselves addicted to its usage.

However, examining the issue of dominance of the WhatsApp on the usage from the perspective of language of interaction on the app, Table 4 below shows that despite the ability of most of the respondents to speak and write other local languages, $88.04 \%$ of them use the English language frequently to chat on WhatsApp.This is followed only by $8.70 \%$ who use still English language, though with Pidgin occasionally. $76.09 \%$ responded that English has a dominating effect on them while using WhatsApp and that they experience challenges as they attempt to use other languages. The table below captures this.

Table 4. See appendix

Figure 4: See appendix

Some of the challenges experienced by the digital natives that limit their use of other languages they are fluent with include the following (as additional notations by the respondents):

"... auto correction does not easily allow a particular word to stay".

"... this is because when I chat in the Igbo language, there are some necessary punctuations in the Igbo language that you cannot find, which are supposed to help convey your actual meaning and intent".

"... Some languages come with some symbols and signs. Looking for those signs sometimes is tiring”.

"Yes, typing in the Igbo language is difficult because it is not one of the programmed languages".

"Yes...I also face the problem of auto-correct when I type in any other language than English".

Table 5 below, however, shows that despite the challenges associated with chatting freely on WhatsApp, some digital natives feel that they cannot avoid its use. Such ones may thus be referred to as conscious and willing slaves to Western digital slavery.

Table 5.See appendix

Additionally, based on the optional comments made by some digital natives, some had the following to say,

"I do not mind being enslaved to WhatsApp usage as long as it gives me the benefits I seek", "I love using WhatsApp and will continue to use it as long as it exists", "I can do without WhatsApp", "Since I am not addicted to it. I can let it go", "My studies are more important to me", "There are other social 
media platforms, why be enslaved to WhatsApp?", "Somehow, I am addicted. I do not mind at all", "WhatsApp does not mean much to me even though I find it useful", "Yes, I am addicted to it because it is beneficial to me."

These comments highlight that some digital natives feel that they can not do without the WhatsApp considering the benefits its usage provides them; however, these are insignificant compared with those that can do without ultimate dependence on WhatsApp.

\section{Discussion of findings}

From the data presented above, it is clear that digital natives are exposed mainly to the use of WhatsApp and other internet-based applications. Also, they are aware of the influence of WhatsApp on them, especially in the area of using the App for communication purposes and the amount of time spent on it. Furthermore, on the issue of perceiving themselves as slaves of the digital colonialism as a consequence of the benefits derivable, which includes smooth communication, especially with loved ones far away $-18.48 \%$ of the sample are unsure, $28.26 \%$ signalled their high dependence on the App and thus their addiction to it. While an impressive 53.26\% outrightly reject the idea of being willing slaves or addicted to WhatsApp usage. Although this percentage of digital natives do not agree to be digitally colonised, they join the other natives in agreeing that irrespective of the fact that they have languages they speak and write fluently other than English. WhatsApp is programmed in a way to allow only the convenient use of the English language, thus creating also that dominating effect which they do not want to accept.

The Media Dependency Theory used as one of the frameworks, for this study notes how people depend on the media for gratification. Individuals tend to be more dependent on the media once they are satisfied with what the media provides. However, this study finds that digital natives depend not only on WhatsApp but also on other internet apps like Instagram and Snapchat. Some categorically assert that they do not need the WhatsApp and as such are not active users. However, such ones are fewer compared to the number of those who actively use the WhatsApp. The Uses and Gratification theory aptly supports the findings of this study as digital natives choose what media works for them. In this case, a good number use the WhatsApp for communication purposes but do not feel that they necessarily depend on them as ones enslaved. This does not entirely agree with Prensky's (2001) view that digital natives only perform best when connected to the internet and appreciate instant gratification.

On the aspect of being slaves to the internet, digital slavery - which is a sense of physical and emotional attachment to technology that it regulates one's life - is not a concept that most of the digital natives studied accepted. Moody (2014) and Illing (2018) noted that digital slaves are not able to master the technological world effectively but are instead enslaved to it. Our study, however, finds that digital natives are averse to being called slaves to the internet, especially WhatsApp. Nevertheless, Anderson (2010) posits that from the waking hours until the end of the day, time (or the whole day) is spent on the internet by digital natives who are constantly checking their phones for whatever purposes. Perhaps, that is the thought of Prensky (2001) when he referred to the natives seeking instant gratification. Even though most of the natives studied do not consider themselves addicted or enslaved to WhatsApp use, previous studies as here mentioned suggests that the amount of time spent can qualify one as being a slave to technology. The study finds that many of the natives spend not less than a range of 1 to 5 hours daily on WhatsApp, let alone on other internet applications.

One can, therefore, a note from the findings that the digital natives in Pan-Atlantic University are highly exposed to the use of WhatsApp and other Internet-based technology or applications. They spend much time chatting on WhatsApp - which may equate them as digital slaves, although the majority do not subscribe to such marking, and only a few admit to being enslaved to WhatsApp use, given the benefits they derive from the technology.

\section{Conclusion}

This paper has argued that the internet is exploitative of the digital natives, and our research indicates that the challenge is relevant to the broader scholarly debates on the issue. The insight into the study deepens the understanding of the topic and gives credence to the relevance of the two theories used - Media Dependency Theory by Sandra Bell Rokeach and Melvin Defleur and the Uses and Gratification Theory by Elihu Kantz and Jay Blumber - to deepen their relevance. In line with Research Question 3, 'Do digital natives see themselves as slaves to the internet via WhatsApp usage?' More research needs to be commenced in order to find out why they do not consider themselves as digital slaves regardless of the overwhelming evidence pointing to that direction. It can then be inferred that digital natives are aware of the influence of WhatsApp on them, but they feel that they are in control. They also are aware of some elements of digital colonialism in terms of the features that make some of them addicted to its use and the amount of time spent on it, and ultimately, the only language convenient for use on the App - the English language. These notwithstanding, it would appear that the amount of time digital natives spend on use of the WhatsApp makes them indeed digitally colonised, even though they do 
not agree.

\section{Recommendation}

Further studies should be directed on this subject to determine the degree of the usage of other Internet-based applications by digital natives, to try out this assertion, a more extensive population sample should be interrogated to ascertain the degree of reliance of the digital natives on social media. This would offer a broader conception as to whether or not they are digitally colonised and governed by their extravagant reliance on internet devices.

\section{Acknowledgements}

1. There was no clash of interest in this work between the writers.

2. This work was not funded by any organisation.

3. The interviews were freely obtained according to an ethical standard without manipulation or coercion.

\section{References}

Ali, M. S. (2017). Decolonizing information narrative: Entangled Apocalyptics, algorithmic racism and the myth of history. A paper presented at IS4SI summit 12-16 June 2017 Gothenburg Sweden.

Anaeto, S., Onabanjo, O., \& Osifeso, J. (2012). Models and theories of communication.Retrieved from https://sappahire.wordpress.com/2012/12/26/153

Anderson, C. (2010). The Web is dead. Long live the Internet. Retrieved from www.wired .com.

Appandurai, A. (1996). Modernity at large. Cultural dimensions of globalization. Minneapolis: University of Minnesota Press.

Barzilai-Norhon, K. \& Mason, R. M. (2010). How executives perceive net generation.

Blumenthal, P. (2018). The techno colonialism of Facebook and Cambridge Analytica. Retrieved from https://www.huffingtonpost.com/entry/facebook-cambridge-analytica...

Cadwalladr, C. \& Harrison, G. (2018). Revealed: 5 million Facebook profiles harvested for Cambridge Analytica in a major data breach. Retrieved from https://www.theguardian.com/news/2018/mar/17/cambridge-analytica-facebook-influence-us-election

Cchub, (2014). How Nigerian students use their phones. Retrieved from www.entrepre-news.com.

Crist, C. (2017). On the mind: What science says about digital natives. Retrieved from pastemagazine.com

Csikasz, S. I. (2017). The study of the gratifications sort and obtained through using enterprise social media: an employee perspective.Retrieved from http:// www.researchgatennet/publications/1258847447_Uses

Dingli, A. \& Seychell, D. (2015). The new digital natives: cutting the cord. New York: Springer

Dingli, A. \& Seychell, D. (2015). The new digital natives: Cutting the chord. New York: Springer.

Ebner, M. \& Shiefner, M. (2010). .Looking towards the future of technology enhanced education: Ubiquitous learning and the digital native. New York: IGI Global.

Eijaz, A. \& Ahmad, R. E. (2011). Electronic colonialism: Outsourcing as discontent of media globalization. American Journal of Contemporary Research. 1(3) 134-143.smit from htpp://www.researchgate.net/publications/325805041

Galtung ,J.(1990).Cultural Violence.Journal of Peace and Research.37 (3),pp.291-305

Guo,L \& Vargo,C.J.(2017).Global intermedia agenda setting:A big dataanlysis of international news flow.Journal of Communication. 67 (4) 499-520.

Hamilton, A. (2016). Introduction to digital colonialism. Retrieved from www.i-human.com.au

Heather, N. K. (2009). Digital natives and immigrants: What brain research tell us. Retrieved from https:/www.questia.com/magazine/1G1-211794589/digital-natives-and-immigrants-what-brain-research

Illing, O. (2018). How we are becoming slaves to technology Retrieved from https://www.vox.com/science-andhealth/2018/3/27/17085282/technology-facebook-social-media-sherry-turkle

Iqani, M. (2016). Consumption, media and the Global South. England: Palgrave Macmillan.

Jandric, P. \& Kuzmanic, A. (2015).Digital postcolonialism. IADIS International Journal on WWW/Internet. 13 , (2), pp. 34-51.

Jardin, P. \& Kuzmanic, A. (2015).Digital postcolonialism.Retrieved from http://www.iadisportal.org/ijwi/papers/2015131203.pdf

Jin, D. Y. (2015). Digital platforms, imperialism and political culture. New York: Routledge

Kwet, M. (2018). Break the hold of digital colonialism. Retrieved from https://mg.co.za/article/2018-06-29-00break-the-hold-of-digital Lefevbre,H.(1974).The production of space .Cambridge MA:Basil Blackwell .

Lin,J. (2008). Research shows internet is rewiring brains. Retrieved from http://newsroom.ucla.edu/stories/081015_gary-small-ibrain

Mathiason, J. (2009). Internet governance: The new frontier of global institutions. New York: Routledge.

McQuail, D. (2010). Mass Communication Theory. London: Sage 
Miller,D.(2004).Information dominance: The Philosophy of total propaganda control. InKamalipour,Y.,\& Snow ,N. (Eds ),War,media and propaganda: A global perspective.Maryland:Rowman and Littlefield Publishers.

Mills, A., Sambuli, N., Varon, J. \& Avila, R. (2017). Digital colonialism: A global overview. Retrieved from www.re-publica.com

Moody, O. (2014). Free yourself from digital slavery. Retrieved from www.chiefrabbi.org.free-youself-fromdigital-slavery-for.a-day-at-least.

Muyiwa, G. K. (2015). The most popular apps in every Nigeria smartphone. Retrieved from https://techpoint.africa/2015/11/06/popular-apps-in-nigeria-smartphone

Noble, S. U. (2018). Algorithms of oppression: How search engines reinforce racism. New York: New York University Press.

Ogunsola, L. A. (2005).Information and communication technologies and the effect of globalization:twenty-first century "digital slavery for developing countries myth or reality. Electronic Journal of Academic and Special Librarianship. 6,1-2, pp.1-10.

Omeruo K.(2012) Africa: A digital colony. Retrieved from www.techtrendsng.com

Omoera, S. O. (2010). Revisiting media imperialism: A review of Nigerian television experience. Retrieved from www.researchgate.net/publication/215710892

Palfrey, J. \& Gasser, U. (2008). Born digital. New York: Basic Books.

Palfrey, J. \& Gasser, U. (2008). Born Digital: Understanding the first generation of digital natives. Pilidelphia: Basic Books.

Patson, P. (2004). Digital natives or digital colonized. Retrieved from https://www.socialworkhelper.com/.../19/digitally-native-or-colonized.

Premium Times. (2018). Nigerian Internet users hit 103 million. Retrieved from https://www.premiumtimesng.com/news/more-news/274828-nigerias-internet-users-hit-103-millionncc.html

Prensky, M. (2001). Digital natives and digital immigrants part 1. On the Horizon. 9, 5, pp.1-6.

Prensky, M. (2001). Digital natives and digital immigrants part 2. Retrieved from www.emeraldinsight.com|doi|abs|10.1108\10748120110424843

Rogerson, S. (2018). Digital existence: A modern way to be. Retrieved www.researchgate.net $\mid$ publications $\backslash 313$

Ronchi, A. M. (2009). eCulture: Cultural content in the digital age. Berlin: Springer.

Schiefner, M. \& Martin, E. (2010). Looking towards the future of technology-enhanced Sefundi: The Journal of South African and American Studies. 16, 2, 156-172.

Similarweb (2018). The most popular apps ranking in Nigeria. Retrieved from www.similarweb.com

Smith, J. (2017). Data is new colonialism. Retrieved from https://indvstrvs.com/data-new-colonialism/

Solon, O. (2017). It's digital colonialism: How Facebook's free internet service has failed its users .Retrieved from https://www.theguardian.com/technology/2017/jul/27/facebook-free-basics-developing-markets

$\begin{array}{llllll}\text { Statista (2018). } & \text { Digital } & \text { Global population } & 2018 . & \text { Retrieved }\end{array}$ https://www.statista.com/statistics/617136/digital-population.

Stole, H. (2018). Why digital natives need books: The myth of digital natives. First Monday.23,10, n.p.

Syallow, M. (2015).Media dependency theory in use. Retrieved from www.academia.edu/9834996/Media_Dependency_Theory_in_Use

Torbel,G.(2019).Social media can predict your behaviour even if you do not use them.Retrieved from www.digitaltrend.com/social media-/social-media-privacy-friends-prediction.

Thussu, D. K. (2007). Media on the move: Global flow and counter flow. London: Routledge.

Varis, T. (1984). The international flow of television programs. Journal of Communication, 34(1), 143-152.

Zengotita, T. (2005). Mediated: How the Media Shape Your World, London: Bloomsbury.

Zur, O. (2011). On the digital immigrants and digital natives: How the digital divide affects families, educational institutions and the workplace. Retrieved from www.researchgate.net $\mid$ publications $\backslash 2672 \backslash 3208$ 
Appendixes

Figure 1: Ball-Rokeach \& DeFleur's (1976) MSD conceptual model

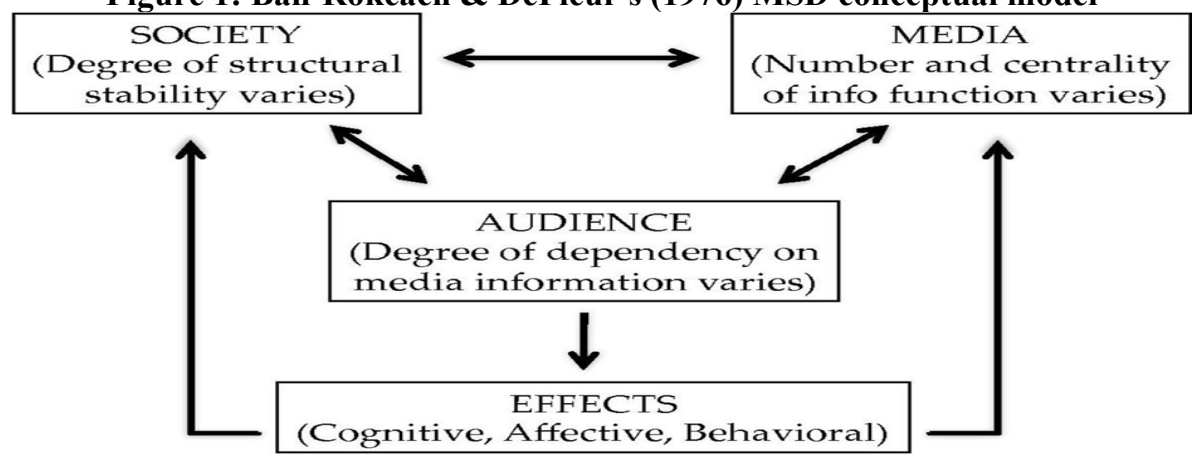

Figure 2: Gender and Age Distribution of Respondents
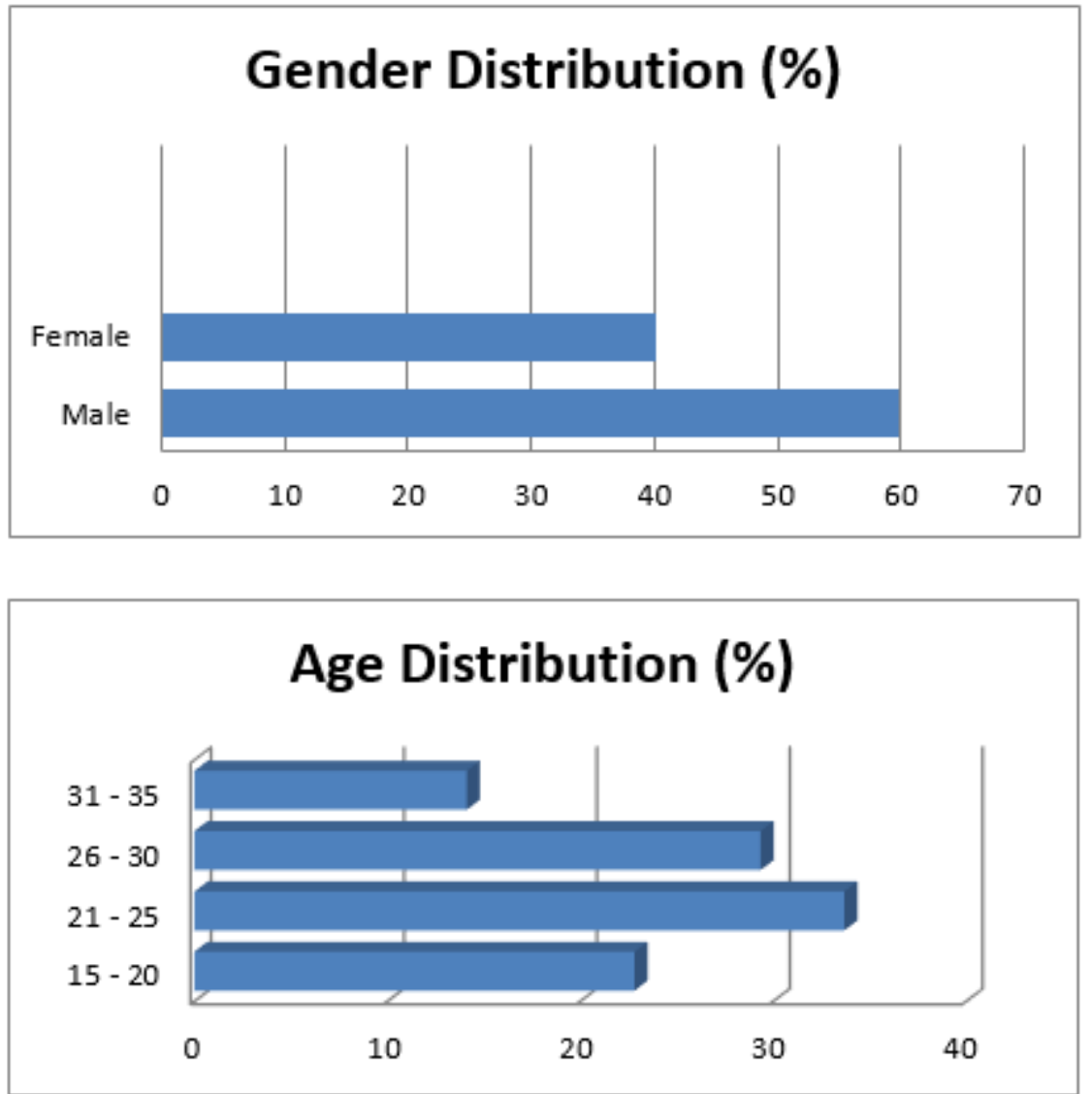

Source: Survey 
Figure 3: Responses on Time Spent Daily on WhatsApp

\section{Time spent daily on WhatsApp}

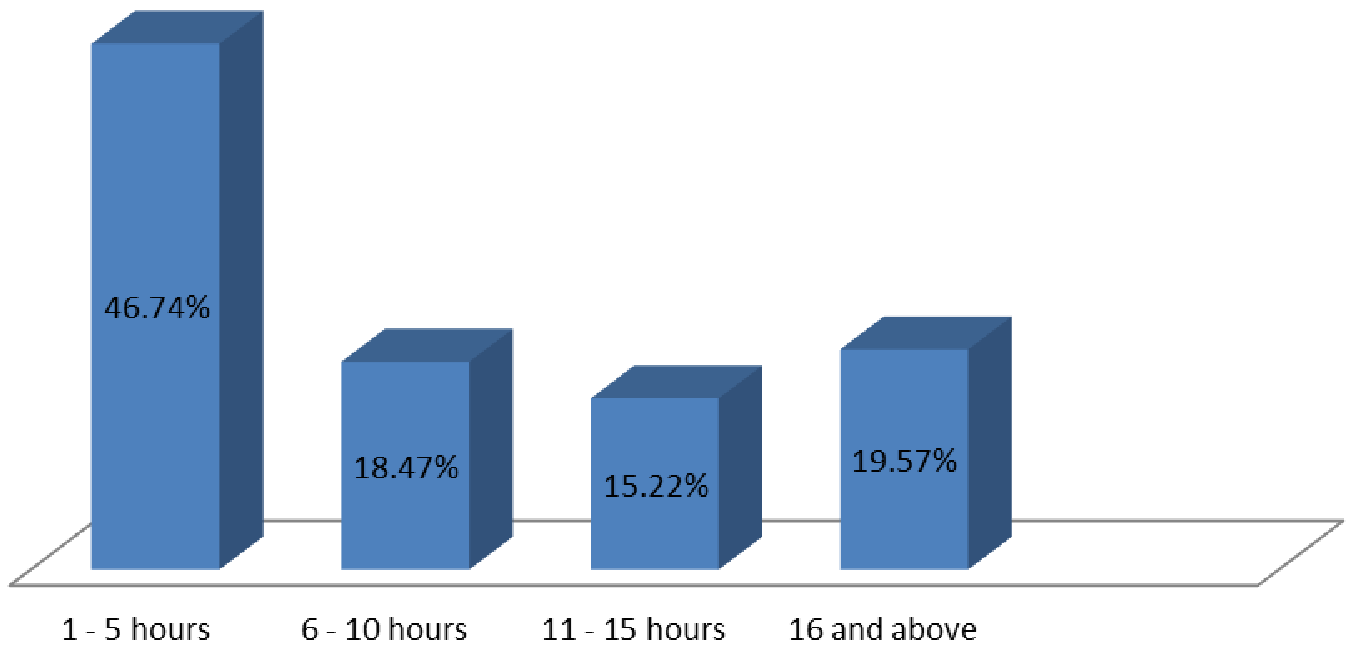

Source: Survey

Table 1. Addiction or Otherwise to WhatsApp Usage

\begin{tabular}{|l|l|l|}
\hline VARIABLES & FREQUENCY $(\mathrm{N}=92)$ & PERCENTAGE $(\%)$ \\
\hline DO YOU FEEL ADDICTED TO THE USE OF WHATSAPP? \\
\hline YES & 26 & $28.26 \%$ \\
\hline NO & 49 & $53.26 \%$ \\
\hline MAYBE & 17 & $18.48 \%$ \\
\hline Total & 92 & $100.00 \%$ \\
\hline
\end{tabular}

Figure 4: Responses to the question Do You Feel Addicted To The Use of WhatsApp?

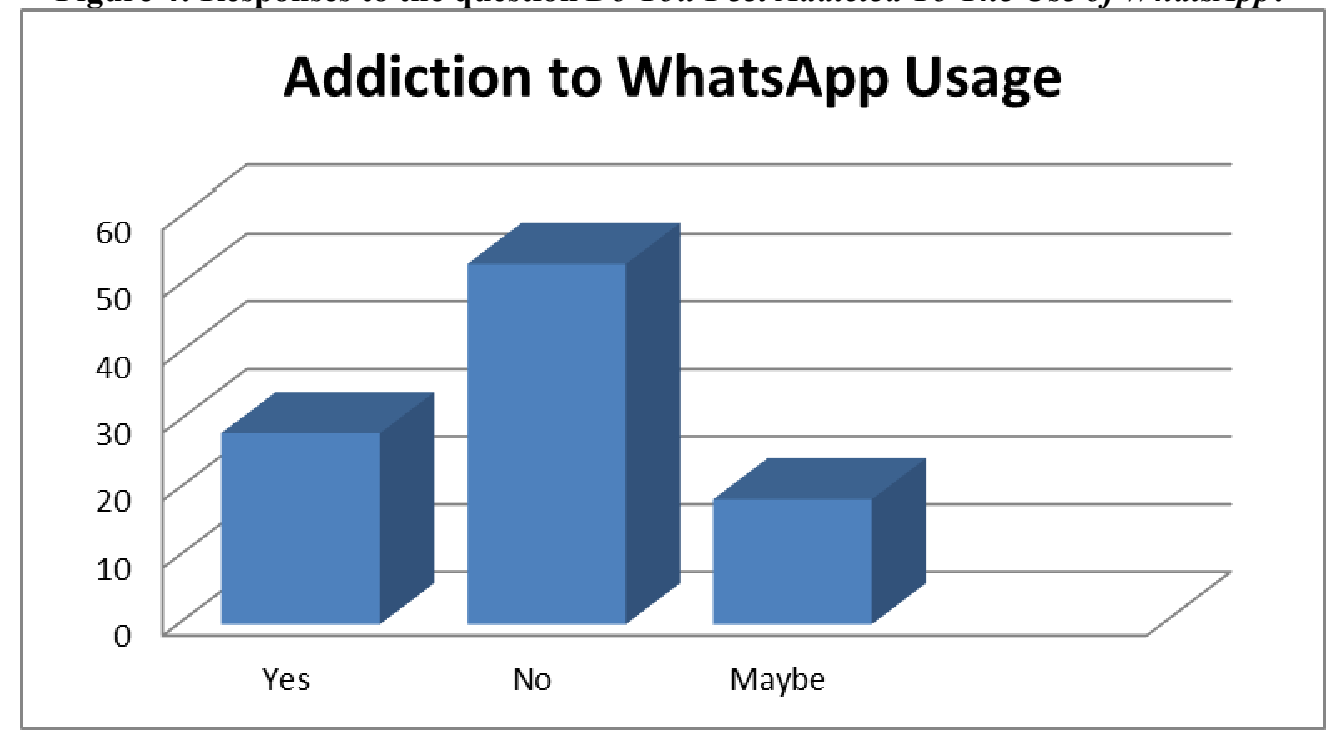

Source: Survey 
Table 2. Languages Spoken and Written Fluently on WhatsApp/Language of Ease

\begin{tabular}{|l|l|l|}
\hline VARIABLES & FREQUENCY (N=92) & PERCENTAGE (\%) \\
\hline LIST OF LANGUAGES THAT ARE SPOKEN AND WRITTEN FLUENTLY \\
\hline English Only & 30 & $32.61 \%$ \\
\hline English \& Yoruba & 17 & $18.48 \%$ \\
\hline English \& Igbo & 12 & $13.04 \%$ \\
\hline English \& Hausa & 2 & $1.55 \%$ \\
\hline English \& Pidgin & 3 & $3.26 \%$ \\
\hline English \& French & 1 & $1.08 \%$ \\
\hline Other Combinations & 27 & $29.98 \%$ \\
\hline Total & 92 & $100.00 \%$ \\
\hline EASE OF USING OTHER LANGUAGES WHILE USING WHATSAPP \\
\hline YES & 48 & $52.17 \%$ \\
\hline NO & 44 & $47.83 \%$ \\
\hline Total & 92 & $100.00 \%$ \\
\hline LANGUAGE FREQUENTLY USED WHILE CHATTING ON WHATSAPP \\
\hline English only & 81 & $88.04 \%$ \\
\hline English \& Pidgin & $8.70 \%$ \\
\hline Others & $3.26 \%$ \\
\hline Total & $100.00 \%$ \\
\hline DO YOU FEEL MORE COMFORTABLE USING ENGLISH WHILE CHATTING ON WHATSAPP? \\
\hline YES & $76.09 \%$ \\
\hline NO & 70 & $10.87 \%$ \\
\hline MAYBE & 10 & $13.04 \%$ \\
\hline Total & 12 & $100.00 \%$ \\
\hline & 92 \\
\hline
\end{tabular}

Figure 5: Language Frequently Used While Chatting on WhatsApp

\section{Language frequently used while chatting}

English only English and Pidgin $=$ Others

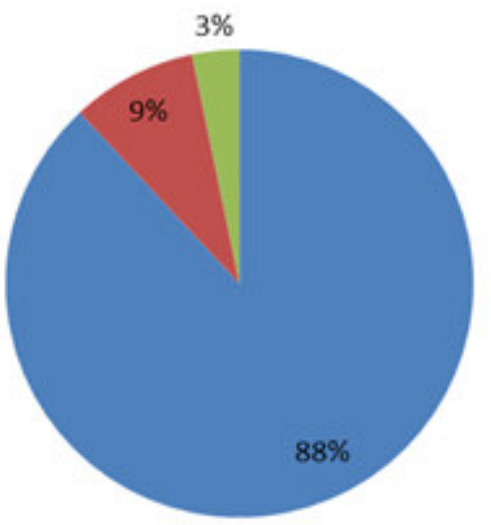

Source: Survey 
TABLE 3 CONSIDERATION OF SELF AS SLAVES CONSEQUENT ON BENEFITS DERIVED FROM WHATSAPP USAGE

\begin{tabular}{|l|l|l|}
\hline SPECIFICS & CHALLENGES & BENEFITS \\
\hline $10 / 5 / 201816: 49$ & $\begin{array}{l}\text { Yes. Auto-correction does not } \\
\text { easily allow a particular word to } \\
\text { stay. }\end{array}$ & $\begin{array}{l}\text { Minimises cost. Saves time } \\
\text { It enables the delivery of bulk contents. It } \\
\text { enables visual chatting. Enables voice chatting. } \\
\text { Helps to communicate to a larger populace via } \\
\text { status update. }\end{array}$ \\
\hline $10 / 5 / 201817: 26$ & $\begin{array}{l}\text { Yes, this is because when I chat } \\
\text { in the Igbo language, there some } \\
\text { necessary punctuation in the Igbo } \\
\text { language that you cannot find, } \\
\text { which is supposed to help convey } \\
\text { your actual meaning and intent. }\end{array}$ & $\begin{array}{l}\text { Secure communication and passage of } \\
\text { information, as in group chats and others; saves } \\
\text { you the cost of buying airtime every time to make } \\
\text { transfer of some media files, e.g. music } \\
\text { files(video and audio), pictures. }\end{array}$ \\
\hline $10 / 5 / 201822: 48$ & $\begin{array}{l}\text { Yes, typing in the Igbo language } \\
\text { is awkward because it is not one } \\
\text { of the programmed languages }\end{array}$ & $\begin{array}{l}\text { Communication, Business Advert, Entertainment } \\
\text { and Information. }\end{array}$ \\
\hline $10 / 6 / 20189: 23$ & $\begin{array}{l}\text { Yes...I also face the problem of } \\
\text { auto-correct when I type in any } \\
\text { other language than English }\end{array}$ & $\begin{array}{l}\text { Quick dissemination of information. It is cheaper. } \\
\text { It is fun to an extent }\end{array}$ \\
\hline
\end{tabular}

